\title{
Drug Eluting Stent : Initial observation in Nepalese patients
}

\author{
B: Rawat, Y. Bhatta, R. Pande, M. Pandey, P. Poudyal, P. Verma, P \\ Agrawal, P. Chandra, R. R. Kasliwal.
}

Recent studies have shown a marked beneficial effect of drug eluting stents in the prevention of restenosis. The total number of patients who underwent PTCA in our institute were 63, out of which 13 drug eluting stents were used in 11 patients. Among these patients, $9(81.81 \%)$ were male and $2(27.27 \%)$ were female patients within the age range of 41 to 70 years.

$9(81.81 \%)$ of these patients had HTN, 6 (54.54\%) patients were dyslipidmic, 7 (63,63\%) patients has history of past MI, $5(45.45 \%)$ had history of angina and $3(27.27 \%)$ of the patients were smokers.

The commonest nature of CAD was SVD in 10 (90.9\%) patients. The RCA was the culprit vessel in 7 (63.63\%) patients and LAD in 6 (54.54\%) patients. In 9 (81.81\%) patients single stent and in $3(27.27 \%)$ patients double stents were used. The drug eluting stents used were infinium (10) and Cypher (6). The size of the stent used were $3 \times 13 \mathrm{~mm}$ (in 4 patients), $3 \times 19 \mathrm{~mm}$ (in 4 patients) and $3.5 \times 14 \mathrm{~mm}$ (in 3 patients). All the patients were adequately covered with asprin and clopidogrel. The GP Ilb/llla inhibitors (Reopro/ Abciximab) was required in 2 patients. The procedural success was observed in all patients. The hospital stay was for 2 days and was uneventful.

All patients were followed up after 1 to 3 months and were symptom free. In conclusion our finding were concurrent with the overall data that drug eluting slents are safe and markedly reduce restenosis rates.

Norvic Escorts international Hospital, Kathmandu, Nepal. 